\title{
Determination of chlorophyll content in case of peach leaf curl disease (Taphrina deformans) with spectral analysis
}

\author{
Riczu, P. ${ }^{1}$, Biró, Gy. ${ }^{1}$, Sulyok, E. ${ }^{1}$, Nagy, A. ${ }^{1}$, Tamás, J. ${ }^{1}$ \& Szabó, Z. ${ }^{2}$ \\ ${ }^{1}$ University of Debrecen, Institute of Water and Environmental Management, \\ Debrecen, 4032. Böszörményi str.138.riczu@agr.unideb.hu \\ ${ }^{2}$ University of Debrecen, Institute for Research and Development, Debrecen, 4032. Böszörményi str. 138.
}

\begin{abstract}
Summary: One of the most important conditions of high quality fruit production is the early detection of phytopathologycal infections. The most dangerous disease of peach (Prunus persica) is the Taphrina deformans, which causes serious damages mainly in the years where the weather condition is cool and wet. In this study, healthy and naturally diseased leaves by peach leaf curl were investigated in the laboratory of University of Debrecen, CAAES, Institute of Water and Environmental Management. Both of hyperspectral measurement and the values of spectrophotometer shown the chlorophyll content of diseased leaves were lower than the healthy samples. Based on the experiments the water status of investigated leaves established the infected leaves contained more water in their tissues.
\end{abstract}

Key words: Taphrina deformans, leaf curl disease, Prunus persica, chlorophyll content, spectral analysis

\section{Introduction}

The botanical name of peach (Prunus persica (L.) Batsch) refers to the putative country of origin, Persia, and Linné (1758) first named the species based on this opinion (Bassi \& Monet, 2008). There are several peach diseases that can attack peach tree and/or fruit. The most common peach tree diseases are brown rot and leaf curl.

The leaf curl disease is caused by the fungus Taphrina deformans (Berk.) (Tul, 1866). First infection is in the spring which comes either from ascospores that have developed on dead fallen leaves or from spores produced by fructifications on the bark, if the fungus is one that also attacks the bark tissue of twigs. Then during the remainder of spring and summer the rapid spread of these fungi by means of spores produced on the killed tissue of the leaves. Economically, leaf spots reduce the yield of plants by bringing a reduction in the available area necessary for photosynthesis to occur (Adekunle et al., 2005). Infection of the host becomes obvious with the appearance of yellow to red or reddish-purple necrotic lesions on the leaf. These ultimately cause curling and deforming of the whole leaf blade and in section the fungus is seen to cause hyperplasia and hypertrophy (abnormal cell division and cell enlargement) of both the epidermis and many underlying cells including the bundle sheath cells; all these cells develop anthocyanins. The surface of the lesion has a velvety appearance and develops a whitish-grey bloom as the asci develop and the surface cuticle is destroyed. No protective fruiting body is formed and the hyphae give rise to modified basal or stalk cells which produce the asci. The asci, under favourable conditions, form a palisade over the surface of the infected part. They are variable in size with a sequence of maturity of ascospores (Kramer, 1973).
The leaf chlorophyll content attracts attention for several reasons: natural or anthropogenic stressors have a direct effect on chlorophyll content, which suggests that a chlorophyll measurement may provide information on the plant physiological state (Lichtenthaler, 1998). The photosynthetic activity determines the biomass production (Ramachandra \& Das, 1986). Chlorophyll content is also linked to nitrogen content and, hence, to photosynthesis (Evans, 1989; Niinemets \& Tenhunen, 1997.

Beyond the reddish, thicker and curl diseased on the entire leaf blade, chlorophyll content of the leaves is disappeared by Taphrina deformans (Gupta, 2004). There are several methods to determine the chlorophyll content of a leaf. The traditional chlorophyll measurements are destructive, timeconsuming and expensive. More recently, remote sensing instruments widespread to detect chlorophyll, using the attenuation of light passing through leaves (Stamps \& Boone 1989). These chlorophyll meters offer the potential for rapid and nondestructive determination of leaf chlorophyll content (Marquard \& Tipton, 1987; Kapotis et al., 2003). Chlorophyll absorbs markedly spectral range between 450-670 nm and healthy vegetation reflects the $40-50 \%$ of the incoming energy between 700-1300 nm spectral ranges due to the internal structure of the leaves, it is influenced mainly by the lignin content of cell wall and the parenchyma structure (Gates et al., 1965).

Based on the spectral characteristic it could be created vegetation indices to evaluate the overall photosynthetic capacity of leaves or productivity of the canopy (Vincini et al., 2008). Some of these indices were then tested several times by different authors on other experimental measurements (Elvidge \& Zhikang, 1995), or using larger reflectance- 
simulated databases based on radiative transfer reflectance models (Broge \& Leblanc, 2001). Making narrowband measurements in the red edge allows these indices to be more sensitive to smaller changes in vegetation health than the broadband greenness vegetation indexes (Sims \& Gamon, 2002). Formerly, it was used a generic calculation of NDVI from spectral valley of red band around 675 and spectral peak in near infrared (NIR) region at $760 \mathrm{~nm}$ to detect chlorophyll content of leaves (Delegido et al., 2011). The Red Edge Normalized Difference Vegetation Index $\left(\mathrm{NDVI}_{705}\right)$, the Modified Red Edge Normalized Difference Vegetation Index $\left(\mathrm{mNDVI}_{705}\right.$ ) and the Modified Red Edge Simple Ratio $\left(\mathrm{mSR}_{705}\right)$ indices are more sophisticated measures of general quantity and vigor of green vegetation than the broadband greenness vegetation indexes. These vegetation indices differ from the generic Normalized Difference Vegetation Index by using bands along the red edge, instead of the main absorption and reflectance peaks and valleys (Sims \& Gamon, 2002).

The aim of this paper was to determine chlorophyll decreasing as well as the water status of the investigated leaves by the effect of Taphrina deformans.

\section{Materials and methods}

The chlorophyll and water content of healthy and naturally diseased leaves infected by pathogenic leaf curl disease were investigated in the laboratory of University of Debrecen, CAAES, Institute of Water and Environmental Management.

Both of diseased and healthy samples were measured in 10 replications. The reflectance measurement was carried out by AvaSpec 2048 Fiber Optic Spectrometer within 400-1000 $\mathrm{nm}$ interval. During the measurement the average spectral resolution was $0.566 \mathrm{~nm}$. This high spectral resolution data provide to calculate some vegetation indices. The AvaSpec 2048 system consists of a spectrometer (detector) and connected by an $8 \mu \mathrm{m}$ core diameter fiber optic standard AvaLight-HAL halogen light source. The accurate measurement was provided by a special spectral sampling back box, since the samples were isolated from the variable external light.

The analytical determination process of modified chlorophyll method was carried out based on Wintermans \& DeMots (1965) adapted by Edwards (1977) were used; and it was evaluated according to method of Felföldy (1980). The healthy and diseased leaves were cut into pieces $(5$ $\mathrm{mm}^{2}$ ), rubbed in mortar with $0.5 \mathrm{~g}$ quartz sand (Spektrum 3D) and $0.5 \mathrm{~g} \mathrm{MgO}$ (Spektrum 3D) and each type of leaf placed in a $30 \mathrm{ml}$ test tube. The test tubes were filled with $10 \mathrm{ml}$ methanol and boiled in a water bath for 10 minutes. Thereafter, they were allowed to cool for 5 minutes. After the cooling, $5 \mathrm{ml}$ of the extract in the test tube was pipetted into a cuvette and placed in SECOMAN Anthelie Light II. UV-VIS spectrophotometer to define the transmission (T) of pigment extracts at wavelength of $750 \mathrm{~nm}, 666 \mathrm{~nm}$ and $635 \mathrm{~nm}$. After the conversion of transmission values to extinctions $(\mathrm{E}=\log$
100/T), chlorophyll content calculated by the following equations:

$$
C=2.57 \cdot E_{666}+23_{653}
$$

where, $\quad \mathrm{C}-$ Chlorophyll concentration of the pigment extract (mg/L),

$\mathrm{E}_{\lambda}-$ Extinction at a given wavelength $(\%)$.

The transmission at $750 \mathrm{~nm}$ is necessary to reduce the noise of the final result.

\section{Results and discussion}

Analysing the spectral characteristic of control and diseased leaves, basic differences could be established (Figure 1). We calculated the average reflectance values of control and diseased samples and determined some narrowband greenness indices which are correlated with chlorophyll content.

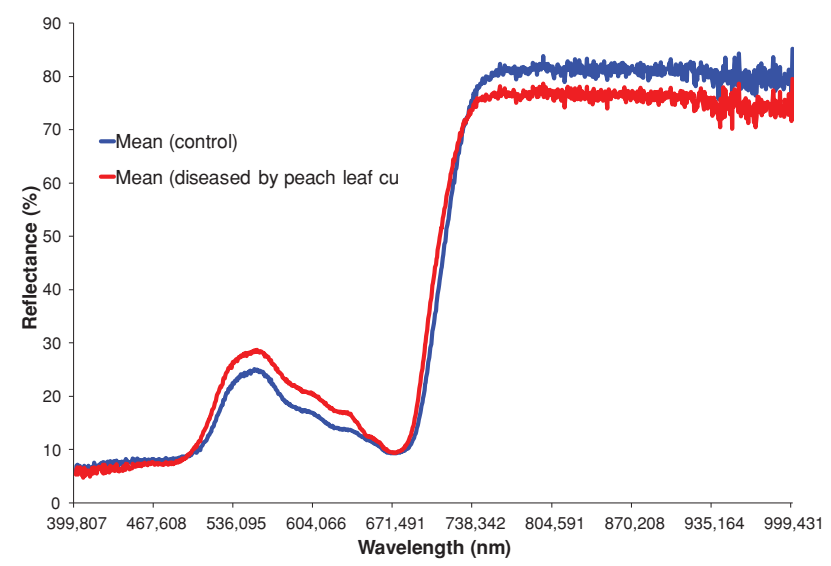

Figure 1. Average spectral profiles of control and infected leaves

In order to numerically compare the results, we calculated the generic Normalized Difference Vegetation Index $\left(\mathrm{NDVI}_{\text {generic }}\right)$ and other three indices. $\mathrm{NDVI}_{705}, \mathrm{mNDVI}_{705}$, $\mathrm{mSR}_{705}$ indices are corrected by the leaf specular reflection to the more sophisticated investigation. On the other hand the generic NDVI was used the reflectance values of valley at red region $\left(\lambda_{672}\right)$ and the peak at near infrared region $\left(\lambda_{780}\right)$. The three other indices were calculated by the red edge. These indices are defined by the following equations:

$$
\begin{array}{cr}
N D V I_{\text {generic }}=\frac{\rho_{780}-\rho_{672}}{\rho_{780}+\rho_{672}} & N D V I_{705}=\frac{\rho_{750}-\rho_{705}}{\rho_{750}+\rho_{705}} \\
m S R_{705}=\frac{\rho_{750}-\rho_{445}}{\rho_{705}-\rho_{445}} & m N D V I_{705}=\frac{\rho_{750}-\rho_{705}}{\rho_{750}+\rho_{705}-2 \rho_{445}}
\end{array}
$$

Based on the results, the generic NDVI values show that in the most cases the healthy leaves had higher NDVI than the diseases by Taphrina deformans. At the same time the more sophisticated measurements - using red edge - established clear differences between the samples (Figure 2). 

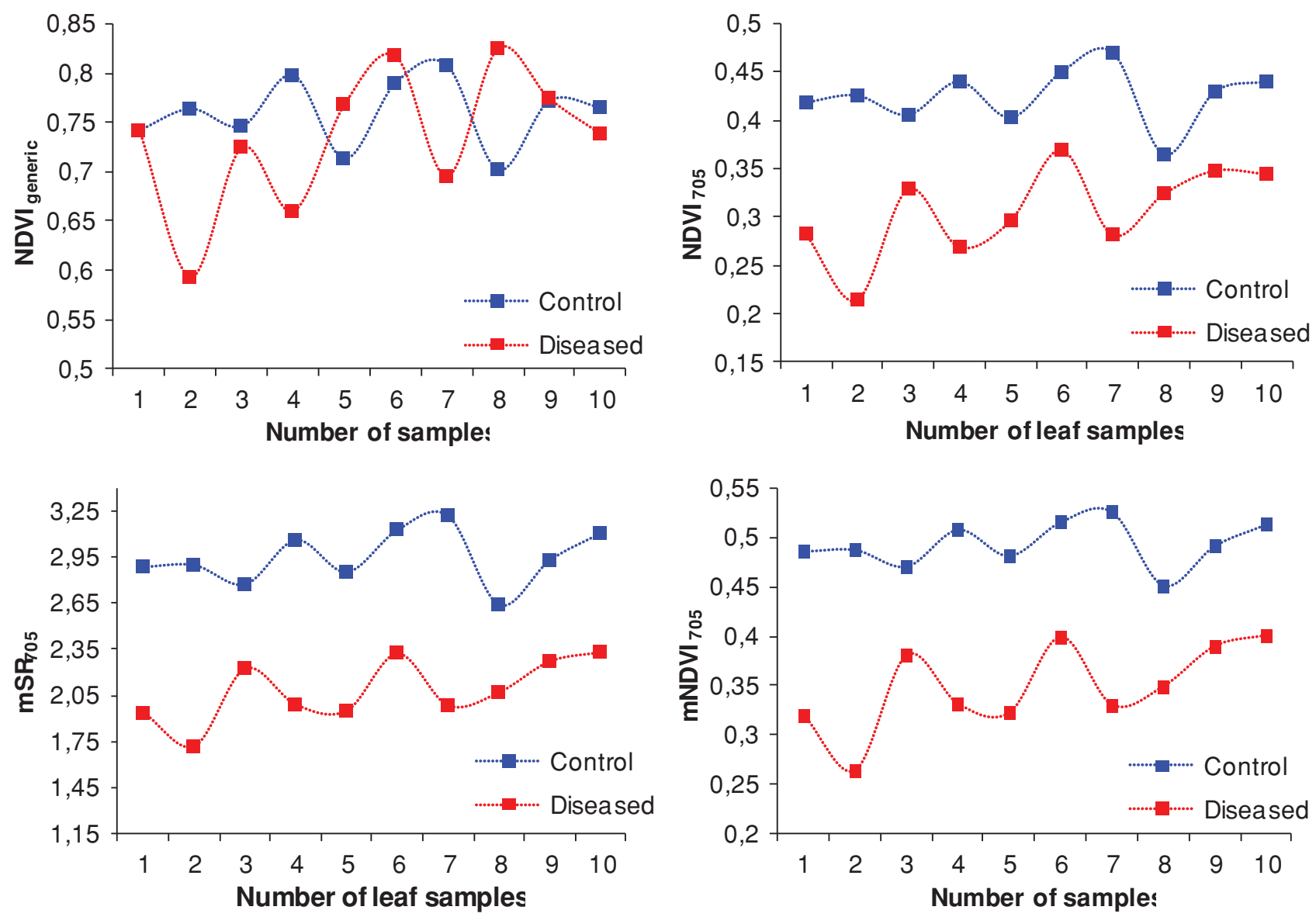

Figure 2.The calculated indices which related to the leaf chlorophyll content

After the spectral measurement we determined the chlorophyll content of leaves with SECOMAN Anthelie Light II. UV-VIS spectrometer as well. The diseased leaves had lower chlorophyll content in all of cases, but we could not find clear linear regression between the diseased and healthy samples.

Analyzing of spectral curves at the water sensitive NIR region could be given opportunities to assessment of water status and water content of healthy and infected leaves. Based on the reflectance values at $\lambda_{900}$ and $\lambda_{970}$ could be established that the diseased leaves had higher water content in the most cases. Verifying the spectral results, the samples were dried to constant weight in the drying oven at $105^{\circ} \mathrm{C}$. Measuring the water loss of dried leaves could be supported that diseased samples contained more water in their tissues, but linear regression could be found between only in case of healthy leaves and WBI $(r=0.66)$.

\section{Conclusion}

Pathogen organisms are frequently caused phytopathologycal and physiological problems in the plant, decreasing the chlorophyll content and photosynthesis, modifying the structure of leaves, thus could influence the fruit production as well. The hymenium of peach leaf curl (Taphrina deformans) could infect then kill the leaf tissue.
Developed nondestructive hyperspectral remote sensing tools could provide to define the early detection of leaf curl based on the calculated vegetation indices. Further experiments are needed to establish the degree of infection based on the less chlorophyll and more water content of diseased leaves. We need to find on the spectral curves such points which typical feature of diseased leaves. In the future it could be served a basis of an airborne vegetation infection mapping to simpler precision pesticide management.

\section{Acknowledgment}

This study is funded by TECH_08-A3/2-2008-0373 and TECH_08-A4/2-2008-0138 projects.

\section{References}

Adekunle, A.A., Uma, NU. \& Oleah, A.M. (2005): Studies on Coloured Leaf Spot Disease of Alchornea cordifolia Caused by Taphrina deformans. Plant Pathology Journal. 4. (1): 150-156.

Bassi, D. \& Monet, R. (2008): Botany and Taxonomy. [In: Rayne DR, Bassi D (eds): The Peach: Botany, Production and Uses.] British Library, London. 1-11.

Broge, N.H. \& Leblanc, E. (2001): Comparing prediction power and stability of broadband and hyperspectral vegetation indices for 
estimation of green leaf area index and canopy chlorophyll density. Remote Sensing of Environment. 76. (2): 156-172.

Delegido, J., Verrelst, J., Alonso, L. \& Moreno, J. (2011): Evaluation of Sentinel-2 Red-Edge Bands for Empirical Estimation of Green LAI and Chlorophyll Content Sensors. 11. (7): 7063-7081.

Edwards, G.E. (1977): The measurement of ozone injury by determination of lead and chlorophyll concentration. Plant Physiol. 60: 606-608.

Elvidge, C.D. \& Zhikang, C. (1995): Comparison of broad-band and narrow-band red and near infrared vegetation indices. Remote Sensing of Environment. 54. (1): 38-48.

Evans, J.R. (1989): Photosynthesis and nitrogen relationships in leaves of C3 plants. Oecologia. 78: 9-19.

Felföldy, L. (1980): A biológiai vízminősítés. Vízügyi Hidrobiológia 9. VIZDOK, Budapest, $264 \mathrm{p}$.

Gates, D.M., Keegan, H.J., Schleter, J.C. \& Weidner, V.R. (1965): Spectral properties of plants. Applied Optics. 4: 11-20.

Gupta, R. (2004): A Text Book of Fungi. APH Publishing. New Delhi. 350 p.

Kapotis, G., Zervoudakis, G., Veltsistas, T. \& Salahas, G. (2003): Comparison of Chlorophyll Meter Readings with Leaf Chlorophyll Concentration in Amaranthus vlitus: Correlation with Physiological Processes. Russian Journal of Plant Physiology. 50. (3): 395-397.

Kramer, C.L. (1973): Protomycetales and Taphrinales. [In Ainsworth GC, Sparrow FK \& Sussman AS (eds): The Fungi.] Academic Press, New York. 33-41.
Lichtenthaler, H.K. (1998): The stress concept in plants: An introduction. Annals of the New York Academy of Science, 851; 187-198.

Marquard, R.D. \& Tipton, J.L. (1987): Relationship between extract- able chlorophyll and an in situ method to estimate leaf greenness. Hort. Science 22: 1327.

Niinemets, Ü. \& Tenhunen, J.D. (1997): A model separating leaf structural and physiological effects on carbon gain along light gradients for the shade-tolerant species Acer saccharum. Plant, Cell and Environment. 20: 845-866.

Ramachandra, A.R. \& Das, V.S.R. (1986): Correlation between biomass production and net photosynthetic rates and kinetic properties of RuBP carcoxylase in certain C3 plants. Biomass. 10: 157-164.

Sims, D.A. \& Gamon, J.A. (2002): Relationships between leaf pigment content and spectral reflectance across a wide range of species, leaf structures and developmental stages. Remote Sensing of Environment. 81 (2-3): 337- 354.

Stamps, R.H. \& Boone, C.C .(1989): Comparison of nondestructive chlorophyll-sensitive photometer and destructive methods of chlorophyll determination. Proceedings of the Florida State Horticultural Society. 101: 333-335.

Vincini, M., Frazzi, E. \& D’Alessio, P. (2008): A broad-band leaf chlorophyll vegetation index at the canopy scale. Precision Agriculture. 9. (5): 303-319.

Wintermans, J.F.G.M. \& DeMots, A. (1965): Spectrophotometric characteristics of chlorophyll 'a' and 'b' and their pheophytins in ethanol. Biochimica et Biophysica Acta 109: 448-453. 